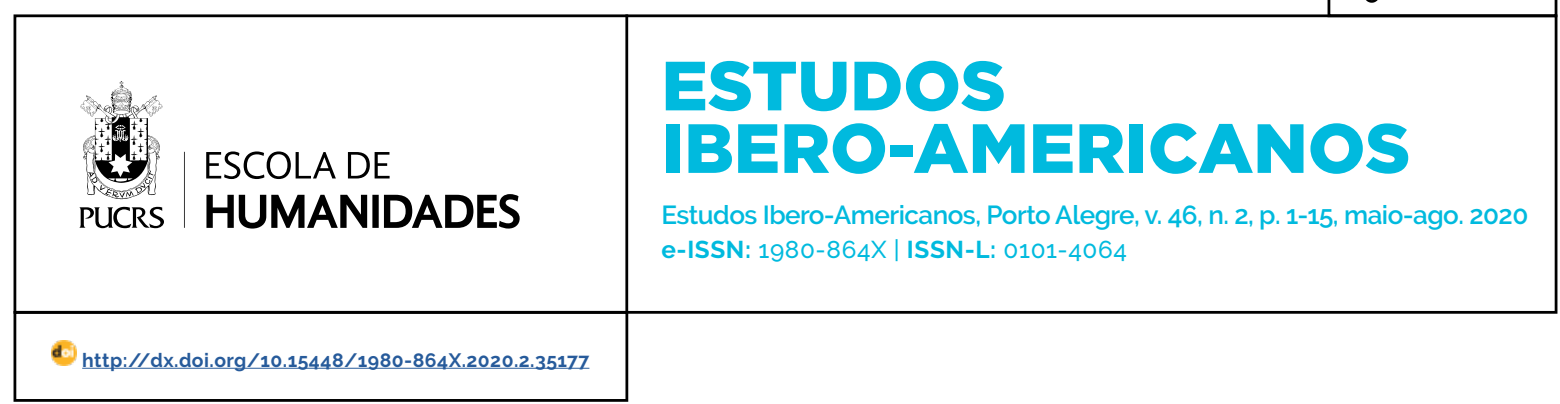

SEÇÃO: DOSSIÊ IMPRENSA, CULTURA E CIRCULAÇÃO DE IDEIAS

\title{
Civique de Gastine (1793-1822) no Correio do Rio de Janeiro: Pacto Colonial Economia Política e as Independências da América
}

\author{
Civique de Gastine (1793-1822) in the Correio do Rio de Janeiro: Colonial Pact, Political \\ Economy and the Independence of America \\ Civique de Gastine (1793-1822) en Correio do Rio de Janeiro: Pacto Colonial, Economía \\ Política y la Independencia de América
}

\section{Paula Botafogo Caricchio Ferreira ${ }^{1}$ orcid.org/0000-0003-3196-3021 paula.botafogo@gmail.com}

Recebido em: 02 ago. 2019. Aprovado em: 16 jan. 2020. Publicado em: 25 ago. 2020.

\section{(c) (1)}

Artigo está licenciado sob forma de uma licença Creative Commons Atribuição 4.0 Internacional.
Resumo: O artigo trata da disseminação, da tradução e da recriação da obra De la Liberté des Peuples et des Droits des Monarques Appelés à les Gouverner (1818) do autor Civique de Gastine (1793-1822) nas publicações do Correio do Rio de Janeiro de 1822. Seu redator João Soares Lisboa é considerado um dos redatores mais radicais da província a atuar no processo de Independência do Brasil e foi o primeiro e único a ser condenado por conluio republicano na história do Império. Graças à divulgação e participação na redação da Representação do Povo do Rio de Janeiro, que pedia a convocação de Cortes do Brasil ao principe regente D. Pedro, sua trajetória se tornou menção obrigatória nas narrativas sobre a história do processo de Independência do Brasil, tanto para valorizar sua iniciativa, quanto para explicar seu radicalismo. Não obstante, é possivel analisar o seu engajamento e o desenvolvimento das ideias de cidadania, de participação e de soberania popular em uma monarquia constitucional pela disseminação, circulação, troca cultural e recriação de publicações ibero-americanas, sobretudo, da obra de Civique de Gastine. Autor pouco divulgado nos periódicos da época, ele é lembrado como "abolicionista" por conta de suas obras que defendiam a abolição da escravidão e a independência de São Domingos. Diante desse cenário, João Soares Lisboa é responsável por sua tradução e releitura, de modo a disseminar as suas ideias como sua principal referência teórica e, ao mesmo tempo, torná- las possiveis em uma monarquia constitucional para o Brasil aos olhos de um redator e negociante pertencente a um grupo de liberais formado pela prática mercantil e impressos em circulação, especialmente no final do século XVIII.

Palavras-chave: Independência do Brasil. Liberalismo. Imprensa. Exilio.

Abstract: The article deals with the dissemination, translation and recreation of the book De la Liberté des Peuples et des Droits des Monarques Appelés à les Gouverner (1818) by author Civique de Gastine (1793-1822) in the publications of Correio do Rio de Janeiro of 1822. His editor João Soares Lisboa is considered one of the most radical writers of the province who acted in Brazil's Independence process and was the first and only to be condemned for "republican collusion" in the history of the Empire. Thanks to the dissemination and participation in the writing of the Representação do Povo do Rio de Janeiro, which asked for the convening of Cortes in Brazil to the Prince Regent D. Pedro, his career became a mandatory mention in the narratives about the history of the Independence process Brazil, both to value its initiative and to explain his radicalism. Nevertheless, it is possible to analyze his engagement and development of the ideas of citizenship, participation and popular sovereignty in a constitutional monarchy through the dissemination, circulation, cultural exchange and recreation of Ibero-American publications, especially the work of Civique de Gastine. An author barely published in the periodicals of the time, he is remembered as "abolitionist" because of his works which advocated the abolition of slavery and the indepen- 
dence of St. Dominic. Given this scenario, João Soares Lisboa is responsible for his translation and rereading, in order to disseminate his ideas as his main theoretical reference and, at the same time, make them possible as a constitutional monarchy for Brazil in the eyes of a writer and dealer belonging to a group of liberals formed by the mercantile practice and printed in circulation, especially in the late eighteenth century.

Keywords: Independence of Brazil. Liberalism. Press. Exile.

Resumen: El artículo trata sobre la difusión, traducción y recreación del libro De la Liberté des Peuples et des Droits des Monarques Appelés à les Gouverner (1818) del autor Civique de Gastine (1793-1822) en las publicaciones de Correio do Rio de Janeiro de 1822. Su redactor João Soares Lisboa es considerado uno de los escritores más radicales de la provincia que actuó en el proceso de independencia de Brasil y fue el primero y el único condenado por "colusión republicana" en la historia del Imperio. Gracias a la difusión y participación en la redacción de la Representação do Povo do Rio de Janeiro, que pidió la convocatoria de Cortes do Brasil al Príncipe Regente D. Pedro, su carrera se convirtió en una mención obligatoria en las narraciones sobre la historia del proceso de independencia Brasil, tanto para valorar su iniciativa como para explicar su radicalismo. Sin embargo, es posible analizar su compromiso y desarrollo de las ideas de ciudadanía, participación y soberanía popular en una monarquía constitucional a través de la difusión, circulación, intercambio cultural y recreación de publicaciones iberoamericanas, especialmente la obra de Civique de Gastine. Un autor poco publicado en las publicaciones periódicas de la época, es recordado como "abolicionista" debido a sus que abogaban por la abolición de la esclavitud y la independencia de Santo Domingo. Ante este escenario, João Soares Lisboa es responsable de su traducción y relectura, con el fin de difundir sus ideas como su principal referencia teórica y, al mismo tiempo, hacerlas posibles en una monarquia constitucional para Brasil a los ojos de un escritor y comerciante perteneciente a un grupo de liberales formado por la práctica mercantil e impreso en circulación, especialmente a finales del siglo XVIII. Palabras clave: Independencia de Brasil. Liberalismo. Prensa. Exilio.

\section{Introdução}

Na Corte, após dar início à redação do Correio do Rio de Janeiro, em 10 de abril de 1822, o negociante de grosso trato e redator João Soares Lisboa protagoniza seu primeiro evento, a organização de um movimento pela reivindicação de Cortes no Brasil. No dia 22 de abril de 1822, foi o primeiro a conclamar o público a reivindicar "já, já, já, Cortes, Cortes, Cortes!!!". Era a solução para manter a união do império português com os ha- bitantes do Brasil gozando dos "mesmos Direitos e Liberdades" que os "Irmãos de Portugal". 2 O pedido do "Povo do Rio de Janeiro" seria feito ao Príncipe Regente, revestido da legitimidade do Poder Executivo e considerado a única garantia na negociação com os deputados de Portugal, em Lisboa. Participou da redação da Representação do Povo do Rio de Janeiro, documento apresentado ao público na edição de seu jornal em que anunciava e convidava a população a comparecer à "loja da Gazeta", a tipografia de Silva Porto, nos dias 21 e 22 de maio, "[...] desde oito horas da manhã até o meio dia, e desde as duas até às seis da tarde [...]" para "ver, ler e assinar a Representação" que seria enviada à "Sua Alteza Real" e para registrar junto à sua assinatura a escolha pelo método direto ou indireto de eleição dos futuros deputados das Cortes do Brasil. ${ }^{3}$ Além disso, em 1823. Soares Lisboa contava que, na época, eles imprimiram e distribuiram "para mais de dois mil exemplares", e afixaram cartazes em lugares públicos da Cidade, informando onde os cidadãos poderiam manifestar sua aprovação à Representação, somando sua assinatura às "mais de seis mil!!!" já reunidas em três dias. ${ }^{4}$

O protagonismo do Correio do Rio de Janeiro e de seu redator nesse movimento foi amplamente explorado nas análises de Lúcia Bastos Pereira das Neves (NEVES, 2003, p. 343-375) e Isabel Lustosa (LUSTOSA, 2000, p. 181-186). A primeira aponta a grande inovação desse movimento ao legitimar, por meio da "vontade popular", o que, em sua leitura, caracterizava uma "[...] nova postura na prática política do Brasil constitucional [...]" (NEVES, 2003 , p. 345). ${ }^{5}$ Definitivamente, foi graças à participação nesse movimento que a trajetória pública de João Soares Lisboa se tornou menção obrigatória nas narrativas sobre a história do processo de Independência do Brasil, tanto para valorizar sua iniciativa quanto para explicar seu protagonismo nos processos judiciais movidos contra ele pelo governo da Corte que o tornariam o primeiro e

\footnotetext{
LISBOA, João Soares. Correio do Rio de Janeiro, Rio de Janeiro, n. 11, 22 abr. 1822, p. 44.

LISBOA, João Soares. Correio do Rio de Janeiro, Rio de Janeiro, n. 33, 18 maio 1822, p. 134

LISBOA, João Soares. Correio do Rio de Janeiro, Rio de Janeiro, n. 7. 23 jul. 1823, p. 32.

Renato Lopes Leite afirma que a convocação de Cortes no Brasil foi um marco do processo de Independência, mais importante do que

o Fico ou o 7 de setembro, considerando-o "[...] o melhor exemplo do poder de fogo da imprensa republicana [...]" (LEITE, 2000, p. 307-308).
} 
único réu a ser condenado na história do Império por conluio republicano (1823) (FERREIRA, 2017).

Para além dessas considerações, é possivel analisar a participação de João Soares Lisboa na reivindicação de Cortes do Brasil através do desenvolvimento das ideias de cidadania, de participação e de soberania popular em uma monarquia constitucional pela disseminação, circulação, troca cultural e recriação de publicações ibero-americanas. Era um negociante que, tendo vindo ainda jovem do Minho para o Brasil, prosperou nos negócios até chegar ao grau de grosso trato no Rio de Janeiro (1818). Entretanto, não tinha formação letrada formal como Silva Lisboa, aprendeu pela prática mercantil e pela instrução disseminada em manuais e outras publicações que podemos chamar de "literatura mercantil". Isso se refletiu em uma forma específica de entender o fazer político, o papel da imprensa e do redator, o que ficou patente com a tradução e a disseminação da obra De la Liberté des Peuples et des Droits des Monarques Appelés à les Gouverner (GASTINE, 1818), de Civique de Gastine (1793-1822), no Correio do Rio de Janeiro.

\section{Circulação e recriação de experiências no espaço público moderno}

Em final de abril de 1822, primeiro mês de publicação do Correio do Rio de Janeiro, João Soares Lisboa "traduzia [para a] instrução [de seus leitores] que não têm conhecimento de linguagens estrangeiras" a obra De la Liberté des Peuples et des Droits des Monarques Appelés à les Gouverner (1818), de Civique de Gastine (1793-1822), o que seria feito ao longo de 10 edições do jornal. ${ }^{6} \mathrm{De}$ acordo com o redator, tratava-se de um "[... judicioso Escritor, cujas preciosas produções de um sublime gênio são pouco conhecidas, segundo pensamos, no Brasil [...]". Esperava dos "Céus que [ficassem] seguras, e bem impressas nas memó- rias de [seus] Concidadãos as eternas verdades" expostas pelo autor francês. Aconselhava seus leitores "que delas [os Concidadãos] [fizessem] uso sem abuso"; com isso pretendia mostrar que "reformar não é destruir". Preparava, assim, o público para a organização do movimento pela reivindicação de Cortes do Brasil a D. Pedro. Ademais, apresentava alguns principios que norteavam suas publicações no Correio do Rio de Janeiro e seu engajamento político, sendo essa sua principal referência teórica nesse momento. ${ }^{7}$

As ideias de Civique de Gastine tiveram papel fundamental, exclusivamente, no Correio do Rio de Janeiro, não tendo sido nem ao menos mencionadas por outros redatores ou correspondentes na imprensa do mesmo período. Somente em 1829. em Minas Gerais, o autor francês voltou a ter seu nome registrado na imprensa, no jornal O Novo Argos, redigido pelo professor e cônego Antonio Ribeiro Bhering (ALMEIDA, 2013). Sem comentários do redator, a citação publicada conclamava a união dos "povos livres" de uma nação para a constituição de um governo "próspero", fundado na "liberdade, moderação e justiça". De acordo com Civique de Gastine,

"[...] a Liberdade não pode existir, se não tem por companheiras a sabedoria, e moderação: aquele que abusa dela, faz-se dela indigno: ela foge, e desaparece, sempre, que é acompanhada da Licença.". ${ }^{8}$

Além de sua patente impopularidade na imprensa, Civique de Gastine e suas obras também não eram mencionados por autores e livros referidos nos requerimentos à Real Mesa Censória para envio ao Brasil (1799-1824), tampouco constavam na lista de livros proibidos ou eram tema de muitas análises da literatura histórica` ${ }^{9}$ Apesar disso, a obra traduzida por João Soares Lisboa no Correio do Rio de Janeiro não sofreria grandes restrições de circulação, tal como ocorria com

\footnotetext{
6 As transcrições de trechos da obra são retiradas da tradução publicada no Correio do Rio de Janeiro que manteve a sua literalidade caso contrário, será mantido o original em francês.

7 LISBOA, João Soares. Correio do Rio de Janeiro, Rio de Janeiro, n. 15, 26 abr. 1822, p. 57. grifo do autor

8 BHERING, Antonio Ribeiro. O Novo Argos, Minas Gerais, n. 6, 18 dez. 1829, p. 3.

9 De acordo com documentos disponiveis no Arquivo Nacional Torre do Tombo, consultados em abr. de 2014 até mar. de 2015 em Lisboa (PT): Real Mesa Censória: Consultas (caixa 184); Requerimento para envio de livros. (microfilme 1351); Requerimentos para entrega de livros retidos. (caixa 147); Requerimentos para entrega de livros retidos (caixa 163); Requerimento para envio de livros. (microfilme 1439); Requerimento para entrega de livros retidos (caixa 147); Requerimento para envio de livros (microfilme 1374) e Requerimento para envio de livros (microfilme 1382)
} 
a maioria dos escritos franceses disseminados no Rio de Janeiro no periodo; as obras escritas a partir de 1815 em defesa da monarquia constitucional eram absorvidas depois de passarem pelo que o jornalista e historiador Marco Morel chama de "filtro da restauração" (MOREL, 2007. p. 187). Civique de Gastine não era um autor tão popular como Adam Smith ou Edmund Burke, mas estava na mesma seara.

A singularidade da escolha e a importância dada ao autor Civique de Gastine por Soares Lisboa estão relacionadas à participação do redator do Correio do Rio de Janeiro em um campo de ideias produzido pela circulação de impressos por meios informais ou clandestinos, disseminação exercida há longa data, mas incrementada da segunda metade do século XVIII ao início do século XIX com o crescimento da produção de reedições e traduções de obras, panfletos, manuais, jornais e outros impressos (DARNTON; ROCHE, 1996; GUERRA, 2002). O presente artigo trata da sua participação na constituição de um espaço público moderno de dimensão atlântica, ocorrida da segunda metade do século XVIII ao século XIX, especialmente, após a eclosão da Revolução Francesa, momento em que já não havia como ignorar a mudança dos tempos (MOREL, 2007, p. 184). Dava-se inicio a debates sobre transformações que ultrapassavam fronteiras imperiais e envolviam todos os estratos sociais. A comunicação pública ampliava-se cada vez mais com uma crescente proliferação, disseminação e circulação atlântica de periódicos, obras, manuais, memórias e outros escritos (TOMICH, 2004). João Soares Lisboa participou ativamente da crescente politização das vivências cotidianas e da proliferação de espaços institucionalizados e informais, ao implodir o espaço privado, até então reservado à discussão política, tornando-a pública, sobretudo, como redator na imprensa de opinião, mas também traduzindo e reinventando a obra de Civique de Gastine (MOREL, 2005; GUERRA, 2002).
A modernidade, conforme definição de R. Koselleck (2006), é mais do que pano de fundo para a apropriação das ideias de Civique de Gastine por João Soares Lisboa. Ela constitui uma forma de entender a relação social entre os tempos, que demonstra o quanto foi inédito o modo de viver as profundas transformações operadas no mundo colonial de 1750 a 1850 e funciona, como afirma João Paulo Pimenta, como uma "[...] ferramenta analítica capaz de oferecer sentido a tais fenômenos [...]" (PIMENTA, 2008, p. 57). ${ }^{10}$

Nessa circulação de impressos, o redator do Correio do Rio de Janeiro reunia e publicava experiências que contribuiam para formular projetos de futuro para o Império do Brasil. Tal como concebido por R. Koselleck, entende-se que experiências são "[...] singulares na medida em que ocorrem e são replicáveis na medida em que são acumuladas". Nesse sentido, a experiência transmitida pela disseminação das ideias de Civique de Gastine por João Soares Lisboa se reflete na história da Independência e na construção do Estado e da nação do Brasil em seu duplo aspecto: "[...] aquele constituido pela experiência e aquele que pode ser derivado dela [...]". Ao analisar os estratos do tempo que a constituem, é possivel visualizar o que há de singular e surpreendente em sua trajetória, bem como o que há de experiências acumuladas que estruturaram suas vivências e apropriações, advindas de histórias em médio prazo (KOSELLECK, 2014, p. 36). Apesar de serem experiências históricas particulares, os diversos contextos na América colonial e recém-independente viviam um fenômeno comum e constituíam uma unidade no que se refere a percepções e a concepções do tempo histórico sobre as transformações advindas da ruptura com o Antigo Regime. Esse conjunto de eventos e a reflexão histórica sobre esses diversos contextos os vislumbravam como espaços de experiência, produzindo um alargamento do espaço de alternativas (PIMENTA, 2008, p. 58; 2015, p. 30).

\footnotetext{
10 Na modernidade, o passado deixava de oferecer ensinamentos definitivos, de consequências inevitáveis, como a História magistra vitae o fazia. Antes, a narrativa do ocorrido passou a ser considerada uma fonte de lições de um tempo cada vez mais próximo e era relativizada pelo aprendizado no presente. Em um tempo histórico acelerado com perspectivas de transformação, o futuro estava também submetido à ação dos atores do presente, não sendo mais pura repetição do passado. Junto às categorias de espaço de experiência e horizonte de expectativa que relacionam os tempos, a categoria de experiência definida por R. Koselleck (2006, p. 267-327) é cara ao unir engajamento ou movimentos sociais e políticos a modos de imaginar, idealizações ou ao que se pode chamar de movimentos e tradições intelectuais.
} 
Tendo em vista a provisoriedade, as incertezas e a aceleração do tempo histórico (DONGHI, 2005. p. 78-135; JANCSÓ; PIMENTA, 2000; PIMENTA, 2011), a publicação da tradução das ideias de Civique de Gastine no Correio do Rio de Janeiro é exemplar para o entroncamento entre uma rede de informações ampliada pela circulação de impressos de variadas naturezas e uma malha já estabelecida anteriormente de trocas comerciais e culturais que era potencializada por demandas políticas advindas da crise, sendo propiciadora, segundo João Paulo Pimenta, de "[...] condições de possibilidade para a criação de um espaço político específico no qual se define a indissociabilidade de destinos entre a América portuguesa e a América espanhola." (PIMENTA, 2015, p. 60). No caso deste estudo, entre porções portuguesas, espanholas, francesas e das 13 colônias. Esta indissociabilidade ou interdependência das revoluções atlânticas (Fernández SEBASTIÁN, 2009, p. 713) alimentava as expectativas em relação ao liberalismo, à modernidade e à construção do Estado e da nação do Brasil, vislumbrando o exercício de um regime monárquico com base nos principios de liberdade, virtude e cidadania pelo uso de conceitos reelaborados a partir de experiências.

\section{A releitura de Civique de Gastine}

No dicionário biográfico de John Fiske e James Grant Wilson, Civique de Gastine (1793-1822) é reconhecido como um reformador das Índias Ocidentais. Nessa obra, que parece ser a única fonte de informações sobre sua trajetória, de seu nascimento até 1818, consta que ele nasceu na França caribenha, em Fort de France, na Martinica, de uma familia abastada. Ainda de acordo com a mesma obra, foi essa condição familiar que permitiu que, em 1803, Civique de Gastine fosse estudar nos Estados Unidos, em Nova Orleans. Em 1809, dirigiu-se para a Filadélfia para estudar leis. Motivado pelo sentimento de admiração por um enfermeiro mulato com o qual conviveu na primeira infância, na Martinica, defendeu os direitos dos negros e a igualdade entre eles e os brancos, sofrendo ataques após a publicação de um panfleto de sua autoria que advogava a causa da emancipação dos escravos. Em 1813. Civique de Gastine discursou publicamente sobre essas convicções e fugiu para Paris sob o risco de ser linchado. Na França, em 1814, escapou do recrutamento para as tropas napoleônicas que travavam a Batalha de Paris, apresentando-se como cidadão estadunidense. Em 1815, iniciou a publicação do L'ami du noir e foi diversas vezes punido com multas e encarceramento por seus artigos serem considerados ofensivos (FISKE; WILSON, 1887, p. 613-614). O dicionário de Fiske e Wilson valoriza Civique de Gastine por seu engajamento em favor da igualdade entre os homens, condizente com a época de sua publicação (1887), quando as forças do Norte já haviam vencido a Guerra Civil dos Estados Unidos.

Nos dicionários biográficos publicados em Paris nos anos de 1823, 1836 e 1852, Civique de Gastine foi lembrado como "abolicionista" por conta das suas obras escritas nos anos de 1819, $1821 \mathrm{e}$ 1822, que defendiam a abolição da escravidão e a independência de São Domingos (MAHUL, 1823. p. 97-99; RABGE; BOISJOLIN; SAINT-PREUVE, 1836, p. 1823-1824; HOEFRER, 1852, p. 603-604).11 Propunha a redefinição das relações coloniais em termos comerciais, de modo a criar vínculos de cooperação econômica benéficos para ambas as nações. Em razão desses escritos considerados "sediciosos" no início de 1822, Civique de Gastine foi exilado por uma decisão extraordinária de Luís XVIII, rei da França, e acolhido pelo presidente do governo haitiano, Boyer. Ele o nomeou secretário de relações exteriores, garantindo-lhe uma pensão anual de cinco mil francos. Por uma subscrição pública, Civique de Gastine foi presenteado com uma magnífica propriedade em Cayes (FISKE; WILSON, 1887, p. 614).

\footnotetext{
11 Além da obra selecionada por João Soares Lisboa, são de autoria de Civique de Gastine: Histoire de la république dd'Haiti. Paris. 1819: Pétition à MM. les Députés des départements sur la nécessité où se trouve la France de faire un traité de commerce avec la republique d'Haït et sur les avantages qu'en retireraient les deux nations. Paris. 1821; Lettre au Roi sur l'indépendance de la république d'Haïti et l'abolition de l'esclavage dans les colonies françaises. Paris. 1821; Lettre au pape sur les prétentions du sacerdoce, et les dangers de revoir le diadème soumis à la tiare. Paris. 1821: Exposé d'une décision extraordinaire, rendue par la régie des Droits réunis qui exile un citoyen français pour un écrit prétendu séditieux. Paris. 1822.
} 
Depois de ter residido por cerca de dois meses em Cayes, dirigiu-se a Porto Principe, onde adoeceu e faleceu em 1822. Enterrado com pompa e homenagens no Haiti, teve seu retrato litografado por E. Duperly. O juiz do tribunal de cassação, Pierre-André, pronunciou o epitáfio de Civique de Gastine e a descrição de seu enterro foi divulgada no jornal haitiano Télégraphe, que o ovacionou por ter sido "un des plus ardens défenseurs des droits de l'homme [...] sensible et vertueux", alçando-o à mesma ordem de importância de uma série de philanthropes da causa escravista, tais como "Grégoire, Lafayette, Foy, Sébastiani, Giudicelli, Benjamin Constant, Laisné de Vilevêque, Morenas, Ternaux, Wilberforce, Clarkson, Webb". Destaca-se que as descrições sobre o ritual de seu enterro e as razões de sua morte não constam no dicionário de Fiske e Wilson, somente nas fontes francófonas consultadas.

O posicionamento de Civique de Gastine sobre a questão escravista contribui para compreender por que suas obras tiveram uma recepção letrada restrita no Brasil e a razão pela qual João Soares Lisboa optou pela supressão da indicação de sua autoria em alguns números do Correio do Rio de Janeiro. Contudo, essa era uma prática comum nos periódicos em uma época, na qual a noção de autoria era mais fluida. ${ }^{12}$ Apesar da fama de Civique de Gastine como "abolicionista", a obra escolhida por João Soares Lisboa, publicada em Paris, em 1818, era anterior ao conjunto de obras escritas a partir de 1819 até 1822, responsáveis pela notoriedade do autor francês e nas quais conclamava a revolução em São Domingos, a emancipação das colônias e criticava a escravidão e o tráfico negreiro. Dessa maneira, Soares Lisboa evitou as controvérsias que a reputação de Civique de Gastine e a tradução de suas ideias pode- riam causar em 1822 na Corte do Rio de Janeiro. Ademais, o redator do Correio do Rio de Janeiro selecionou justamente a obra do autor francês que mais convergia com suas ideias publicadas nesse jornal, já que em nenhum momento posicionava-se contra o tráfico ou pela abolição da escravidão. Nela, Civique de Gastine tinha como premissa a rearticulação dos laços coloniais e não se posicionava sobre a questão escravista, sendo bem menos favorável aos haitianos, classificando o seu governo como "despótico". O autor entendia que os recém-libertos da escravidão, além de pecarem pela falta de "civilização", o que os incapacitava para construírem um governo realmente "liberal", se espelhavam nos seus antigos senhores que, por sua vez, viviam sob o regime de uma monarquia "despótica".13

Sobre as ideias registradas na obra escolhida por João Soares Lisboa, pode-se dizer que convergiam com o movimento francês que pensava a Restauração Monárquica, indagando os modos de governo da monarquia constitucional e de rearticulação das relações coloniais, evitando a violência e os desastres das revoluções. Ao analisar essa mesma obra, a cientista política Jennifer Pitts afirma que o autor francês utilizava a economia política para argumentar moral e politicamente a favor da emancipação das colônias, vista por ele como etapa necessária para a sobrevivência do governo liberal da metrópole (PITTS, 2012, p. 09). A autora entende que Civique de Gastine compartilhava da ideia central dos escritos de Benjamin Constant de que

"[...] the liberal project of representative government at home was inextricable from an international politics of peaceful commerce and the mutual respect of sovereign states. [...]" (PITTS, 2012, p. 10).

\footnotetext{
12 João Soares Lisboa indicou a autoria dos capítulos 01 ("Um povo é em tudo comparado a um indivíduo") e 02 (“Um pai está para sua familia como um rei está para seu povo e vice-versa") (LISBOA, João Soares. Correio do Rio de Janeiro, Rio de Janeiro, n. 15. 26 abr. 1822 n. 18, 30 abr. 1822; n. 19, 1 maio 1822). Por sua vez, não mencionou o autor no capítulo 03 ("O que acontecerá infalivelmente, se um Pai, ou um Rei quiser conservar sobre seus súditos os direitos que tem sobre eles além do termo que a natureza lhe estabelece"), 04 ("Das perseguições políticas e religiosas"), 10 ("Das colônias, dos direitos que a mãe pátria tem sobre eles, e do momento da sua liberdade concedido pela natureza"), 17 ("Daqueles que são Cidadãos em um Estado, e daqueles que o não são"), 08 ("Da civilização, e sua marcha") e 23 ("Para os honestos Eclesiásticos amigos da humanidade, e outras personagens piedosas que crendo a sã Filosofia, a sábia Liberdade, e a representação Nacional, opostas aos dogmas do culto que professam, não terão achado suficientes as provas que temos dado") (LISBOA, João Soares. Correio do Rio de Janeiro, Rio de Janeiro, n. 31, 15 maio 1822; n. 32, 17 maio 1822; n. 34, 20 maio $1822 ;$ n. 35,20 maio 1822; n. 36, 21 maio 1822; n. 37, 23 maio 1822; n. 38, 24 maio 1822).

13 LISBOA, João Soares. Correio do Rio de Janeiro, Rio de Janeiro, n. 32, 17 maio 1822, p. 131-132.
} 
Nesse sentido, a concepção de "economia política" apresentada pelo autor francês também contribui para compreender a preferência de João Soares Lisboa por ele, relacionada com sua formação letrada mercantil. Ao que tudo indica, esse capítulo da obra original foi o que mais o fascinou ou impactou de toda a obra de Civique de Gastine. Não obstante, não o traduziu e publicou no Correio do Rio de Janeiro, resistindo em revelar publicamente sua concepção sobre o que considerava "força moral", "riqueza da nação" e "lucro" ou a debater esses temas como redator e na imprensa, por exemplo, enfrentando autoridades no assunto como José da Silva Lisboa.

No capítulo de número 21, intitulado "De ce qui fait la richesse réelle d'une nation", Civique de Gastine desenvolvia sua concepção de economia politica, pensada necessariamente sob o prisma da questão colonial, contudo, sem a conclamação imediata das colônias à Independência. Nesse caso, o autor francês privilegiava a ideia de uma espécie de emancipação gradual, opunha os valores de "l'ambition" e "vengeance" aos princípios de "un être sage et raisonnable" para definir os caminhos que os "peuples" deveriam tomar em relação ao quadro internacional das nações e à sua economia. Definia que a "richesse réelle d'une nation", apesar de variar "suivant son âge e son caractère", consistia em sua "indépendence", "[...] pouvant se procurer chez lui de quoi satisfaire à tous ses besoins, a le bonheur de se soustaire à toute dépendance de ses voisins", mantendo o comércio como elo entre os "peuples" (GASTINE, 1818, p. 104-105). Entretanto, essa "indépendence" não era benéfica, caso fosse conquistada com o prejuizo das relações com seus vizinhos, por exemplo, ao privá-los de um item que eles "ne puissent se procurer ailleurs", o que motivaria a "vengeance". Defendia o princípio de construção de um sistema de cooperação econômica e política entre "peuples indépendans" (GASTINE, 1818, p. 105-106).

Civique de Gastine submetia as ações econômicas a um código moral condizente com a formação mercantil de João Soares Lisboa e incluía as ideias de "liberdade, civilização e razão". Apesar de não ter traduzido e publicado esse capítulo no Correio do Rio de Janeiro, era ele que fundamentava a formulação da filosofia politica do autor francês e norteava toda sua obra, associando a "economia do indivíduo" e a "economia política". O raciocinio era que, por "natureza", os individuos e as nações eram formados por "forças morais e físicas" e que o equilibrio entre elas determinava as diretrizes da sua "economia" que, caso seguidas e respeitadas, produziriam sua "prosperidade". O "fisico" e o "moral" deveriam "[...] chegar juntos à perfeição, que não podem alcançar um sem o outro, sem ocasionar, na economia do indivíduo um desarranjo considerável [...]"14. Isto é, da mesma maneira que as operações mercantis deveriam respeitar uma determinada conduta moral, observada no foro intimo do sujeito e relacionada à moderação: "sábia", "razoável" e definida por virtudes em detrimento de vícios; a economia de um "povo" e, como se verá, o modo de seu governo, deveria respeitar uma conduta correlata. Segundo Civique de Gastine, era isso que possibilitava e mantinha a liberdade de um "povo" em sentido amplo, de comércio, na relação com outros "povos", do "povo" em relação ao governante ${ }^{15}$. Nesse sentido, diferenciava "opulência" de "richesse", sendo a primeira o acúmulo de bens e a segunda, preferivel, definida pela "indépendance". A busca de riqueza pelos individuos e nações era "sage" e "raisonnable" quando respeitava o compromisso em mantê-la junto à "liberté" (GASTINE, 1818, p. 106).

Na definição de riqueza da nação, Civique de Gastine dava papel primordial à agricultura na época dos "peuples jeunes", mas depois, "ils lles produits de l'agriculture] ne suffisent plus pour satisfaire aux besoins des nations éclairées". Explicava que, da mesma forma que as nações se tornam mais "éclairées", adquirindo conhecimentos sobre "arts et des sciences", seus produtos deveriam ser somados à "la richesse réelle d'une nation". O que estava por trás dessa argumentação era a eleição do comércio como uma das marcas da

14 LISBOA, João Soares. Correio do Rio de Janeiro, Rio de Janeiro, n. 32, 17 maio 1822, p. 130; n. 35, 21 maio 1822, p. 144.

15 Sobre a ideia de uma "educação de si" como princípio para o governo, convertido em virtude pública (SCHIAVINATTO, 2017, p. 105-149). 
"civilização" de uma nação, o que era internalizado no processo de "regime de aprendizagem mercantil" (PEDREIRA, 1995, p. 1-61) por meio da mesma afirmação comum aos manuais de comércio ou mesmo às cartilhas para a educação de primeiras letras (GASTINE, 1818, p. 106). ${ }^{16}$

Civique de Gastine mudou sua concepção sobre a questão colonial a partir de seus escritos de 1819. Nelas, não mais enxergava a possibilidade de rearticulação dos laços coloniais, passava a condenar a colonização como conquista e a aclamar todas as colônias à emancipação. Diante da reputação independentista e abolicionista do autor francês, construida por essas obras, para João Soares Lisboa, os pontos de afinidade entre as ideias de Civique de Gastine publicados em De la Liberté des Peuples et des Droits des Monarques Appelés à les Gouverner e as publicações do Correio do Rio de Janeiro não só enfraqueciam oposições contra sua disseminação pública como permitiam a utilização de suas reflexões para o contexto do império português, registrando as suas passagens que discutiam a questão colonial e apontavam a Biblia enquanto fonte de conhecimento político. Não obstante, João Soares Lisboa julgava que alguns capitulos dessa obra apresentavam questões mais polêmicas ou com as quais ele também não concordava e que poderiam ser duramente criticadas na imprensa fluminense e atribuidas também a ele; por isso, omitiu-os da sua tradução e publicação no Correio do Rio de Janeiro ${ }^{17}$. Também deixou de lado elaborações mais pragmáticas e especíicas sobre leis, impostos e sentenças e reordenou os capítulos ${ }^{18}$.

Com a publicação da tradução, Soares Lisboa mostrava seu domínio do francês a ponto de considerar sua versão digna de disseminação pública. Apesar de não gozar de formação universitária, a habilidade de leitura e tradução do francês habilitava o redator do Correio do Rio de Janeiro a dialogar com uma camada de homens que compartilhavam um acervo de leituras amplamente disseminadas no mundo acadêmico português, como Peter Burke, Benjamin Constant e Montesquieu (VARGUES, 1997, p. 31-45). Prática textual corrente na época, Soares Lisboa recriava a obra do autor francês, tornando-se um coautor. Assim, reforçava a ideia apresentada por Civique de Gastine de uma transição da monarquia absoluta à constitucional de forma pacífica, com a adesão do "povo" e do rei, tal como ele também imaginava que deveria ser a convocação de Cortes do Brasil.

\section{A questão colonial e as independências}

De acordo com a filosofia política definida por Civique de Gastine, a "liberdade" era o motor e o fim do governo dos "povos". Por isso, afirmava que a "forma de governo de um Povo deve mudar" no sentido de "[...] tornar-se de mais em mais liberal à proporção do progresso dos conhecimentos [...]". Nesta progressão, com o passar do tempo, os "povos" se "civilizavam", ganhavam complexidade econômica, política e cultural que proporcionava necessidades que não eram mais supridas por um pai, "chefe" ou "rei". Dessa maneira, atrelava o governo dos "povos" e a "economia" das nações à progressão, política e econômica, de elementos tais como "civilização, liberdade, prosperidade e independência", definindo as relações internacionais a partir do comércio, pela transformação das relações entre as nações. ${ }^{19}$

Para o autor francês, a questão colonial era um ponto essencial à consolidação da liberdade no

\footnotetext{
16 Em Tesouro de Meninos de Pierre Blanchard (1851), a felicidade em sociedade era garantida pelo domínio das paixões naturais resguardada pela reflexão dos homens sobre a moralidade das suas condutas e pelo respeito às leis humanas e divinas. Todavia, essa não era completa se os homens não se conservassem. Nas obras dirigidas à instrução dos meninos, era na busca do sustento mútuo que o comércio assumia um lugar primordial na sociedade, sendo um signo de civilização e complexidade das relações em sociedade (BLANCHARD, 1851, p. 18-19).

17 Dos 23 capítulos que compõem a obra original, Soares Lisboa publicou a tradução de somente oito, sendo omitidos os seguintes: IV "De la royauté en Europe, et de sa décadence"; $V$ "De la religion suivant l'âge et les lumières des peuples"; VII. "De l'opulence du clergé"; IX. "De la force civique et militaire d'un Etat"; XI. "Des lois pénales"; XII "De la peine de mort"; XIII. "Du régicide ou parricide"; XIV "Des impôts et de la manière dont ils sont établis": XV "Des traités de paix entre les puissances"; XVI "Des écrits intitulés MANIFESTES, précédant les déclarations de guerre"; XVIII. "Des grandes fermes"; XIX "Des grandes villes"; XX "De la loi agraire"; XXI "De ce qui fait la richesse réelle d'une nation" e XXII "Des arts mécaniques" (GASTINE, 1818, p. 25-35;49; 58;61;68-72;76;88-109).

18 João Soares Lisboa deslocou o oitavo capítulo da obra original, publicado entre o de número 17 e o 23 (LISBOA, João Soares. Correio do Rio de Janeiro, Rio de Janeiro, n. 34, 20 maio 1822, p. 139, n. 35, 20 maio 1822, p. 144, n. 37, 23 maio 1822, p. 152).

19 LISBOA, João Soares. Correio do Rio de Janeiro, Rio de Janeiro, n. 19, 01 maio 1822, p. 76.
} 
"governo dos povos". De acordo com Civique de Gastine, a "colônia leral para um povo, o que um filho [era] para um pai". Dessa maneira, relacionava as bases de sua reflexão sobre "liberdade", "leis naturais" e "graus de amadurecimento de um povo" à análise dos vinculos coloniais. Em sua obra, a "mãe pátria", a metrópole, se manteria no poder enquanto tivesse a vantagem da "força fisica e moral" sobre os colonos, baseada na "dependência". Os colonos

"[...] não procurarão sacudir o jugo, nem proclamar a sua independência, pelo contrário, os laços que os prendem a ela serão tanto mais fortes que consistirão $1^{\circ}$ nas privações de colônia e $2^{\circ}$ nos sacrifícios da mãe-pátria".

Entretanto, como os filhos, as colônias, por "força da natureza", amadureciam e proclamavam sua "liberdade" e "independência", constituindo governos constitucionais. Segundo Civique de Gastine, o "voto da natureza", sua finalidade última, era a de tornar todos os "povos livres" e quem se opunha a isto cometia um "crime" contra a Natureza e os designios de Deus. ${ }^{20}$

De acordo com sua concepção de história, quando a colônia já não era totalmente dependente da "mãe pátria", restava a ela tornar-se aliada, contudo, geralmente acontecia o contrário e a metrópole via a colônia como "seu maior inimigo". Para Civique de Gastine, isso era "simples e natural"; se a mãe pátria fosse sábia e renunciasse aos seus "direitos", sem necessidade de "tribunais" e uso de armas, faria dos colonos seus aliados, "o que [lhe seria] extremamente vantajoso debaixo de sobrado interesse da guerra e do comércio.". 21 Caso contrário, assim como o direito de "dominação do pai sobre um filho não era eterno", não havia como se determinar a um "povo" que estivesse "eternamente debaixo de uma dominação qualquer", pois, por natureza, todos são livres e "nenhum ser do mundo tem direito de dirigir tuas ações".22 Assim, a partir da provisoriedade do direito de dominação, Civique de Gastine apontava o direito de "resistência". Caso um pai, o rei ou a metrópole pretendessem ainda governar o filho ou a colônia, mesmo depois de amadurecidos e adultos, o acordo entre pai e filhos cessava e eles, apesar de ouvirem os conselhos do pai, não receberiam mais suas ordens. ${ }^{23}$

A ideia de uma "emancipação gradual" e do uso da metáfora da família apresentada na obra de Civique de Gastine, traduzida e publicada no Correio do Rio de Janeiro, era semelhante à disseminada em outros periódicos publicados na Corte fluminense, tal como $O$ Papagaio e $O$ Espelho (NEVES, 2003, p. 218-219, 248). De 1821 até cerca de setembro de 1822, suas publicações remetiam à "família portuguesa" para justificar a união entre Brasil e Portugal como reinos "irmãos" e a adesão do governo da Corte no Rio de Janeiro aos vintistas. Também os jornais publicados em Portugal, tal como o Astro da Lusitânia, e dos exilados portugueses, como o Correio Braziliense, em Londres, de redação de Hipólito da Costa, compartilhavam da mesma visão de definição de identidade portuguesa (ALEXANDRE, 1993, p. 713-729; TENGARRINHA, 2013, p. 203-209, 317355: ALVES, 1992, p. 98). Ademais, a metáfora da "familia" também estava presente na definição de "nação portuguesa" dos deputados "integracionistas" que pronunciavam a ideia de que os

"[...] portugueses em todas as quatro partes do mundo são membros da mesma familia, formam todos a mesma nação, e seguem todos o mesmo exemplo [...]",

sendo para eles o reino de Portugal a "mãe pátria", que deveria ser detentora da sede do império (ALEXANDRE, 1993, p. 574).

Antes disso, na década de 1810, essa leitura do processo de independência das colônias era amplamente disseminada nos discursos dos hispano-americanos que reivindicavam autonomia no governo das juntas e negavam-se a admitir a legitimidade da monarquia espanhola sob domínio napoleônico. De forma semelhante a Civique 
de Gastine, os hispano-americanos chamados a essa época de patriotas se inspiravam nas ideias do Abade De Pradt para propagandearem a independência na América espanhola. Justificavam que as colônias eram "filhas" da metrópole e que, no início do século XIX, haviam chegado ao momento de sua "maturidade", quando o filho deveria se tornar independente da "mãe" (QUIJADA, 2005, p. 11; MOREL, 2017, p. 149-164).

Em 1822, no desenvolvimento das ideias publicadas no Correio do Rio de Janeiro, a ideia de uma "emancipação gradual" reforçava a concepção de uma humanidade única, mas que se apresentava em variadas formas, conforme seus diversos "estágios de evolução" em relação à "perfectibilidade humana". Se, de acordo com a historiadora Mônica Quijada, o grande mérito de De Pradt foi ter aplicado concretamente às colônias espanholas uma teoria do amadurecimento, igualmente, a formulação de Civique de Gastine fundava-se na ideia de a independência ser um processo inevitável, que, todavia, se desenvolveria "gradualmente" e de "modo natural" como o transcorrer da vida de um indivíduo. Nessa perspectiva, suas formulações sobre a questão colonial privilegiavam a negociação dos vínculos coloniais, negando qualquer rompimento imediato e a todo custo da colônia com a metrópole. Nesse sentido, seriam bem aceitas na imprensa e mesmo pelos homens dos círculos mais estreitos da Corte, tal como José Bonifácio. Assim, a escolha pelo autor francês unia a convicção de João Soares Lisboa no início de 1822 de que a união do Brasil e Portugal sob novas bases era o caminho político mais benéfico, somado ao apreço nele internalizado pela negociação e comércio como elos entre os "povos".

\section{O pacto social e as "leis naturais imutáveis e eternas"}

Outro ponto decisivo para entender a motivação da publicação da obra de Civique de Gastine no Correio do Rio de Janeiro é o fato de a metáfora da familia usada pelo autor não explicar somente as relações coloniais, mas por ser também uma analogia para compreender as transformações nos governos. No primeiro capítulo da obra, intitulado "Um povo é em tudo comparável a um indivíduo", o autor expunha sua teoria de fundação do pacto social e interpretava o governo como uma esfera das relações sociais que, por isso, funcionava de forma semelhante a outras, inclusive a doméstica. Nesse sentido, o modo com que desenvolvia sua teoria política recuperava os ensinamentos da tradição humanista, presentes no que se chamava de "polícia" nos "manuais de civilidade" da segunda metade do século XVIII e que envolvia a administração da "casa" (VAZ, 2002).

O autor francês teorizava sobre o governo pelo micro e ampliava o seu entendimento ao macro, estendendo a lógica das relações familiares à administração da sociedade e da monarquia constitucional. Isso favorecia o entendimento de uma volumosa gama de homens que, como João Soares Lisboa, tiveram sua formação letrada por escritos disseminados, sobretudo, desde o final do século XVIII e início do XIX, e que faziam parte da cultura de escrita e de leitura dos negociantes, observadas nas instruções de "manuais de comércio" (PEDREIRA, 1995, p. 62-124), tal como um dos mais célebres, intitulado O Guarda-Livros Moderno (MENDONÇA, 1816).

Com modo argumentativo semelhante, Civique de Gastine comparava o indivíduo ao "povo" com a finalidade de explicar a fundação e exercício do pacto social. O "povo" amadurecia e passava pelas mesmas etapas da vida que um individuo: "nascimento, infância, mocidade, virilidade, velhice, decrepitude, e morte". ${ }^{24}$ Em cada um desses períodos, possuía uma determinada capacidade "física e moral" que mudava conforme a força da própria "natureza", pelo "amadurecimento natural" proporcionado pelo avanço de sua idade e o incremento de suas "ciências", "artes" e "civilização". 25 Nesse sentido, a formulação dos governos, especialmente suas leis, deveria subordinar-se às características e ao estágio no qual o determinado "Povo" se encontra. Ademais, 
eram necessárias transformações de acordo com as "[...] mui grandes mudanças em fisionomias, caráter, temperamento, costumes e moral [...]" provocadas pelo tempo. O que havia no governo de perene, estável e inescapável em todos os estágios era o exercício das leis da natureza que eram "imutáveis e eternas" e deveriam ser garantidas no governo. ${ }^{26}$

A partir disso, explicava que, através de alianças e reuniões de familias, formavam-se os reinos. Em um processo que se desenvolveu com "consentimento", sem coação, o "[...] pai ou o chefe da mais numerosa [familia] teria conservado sobre todas os poderes que tinha sobre a sua". Nesse processo, não era das "conquistas" que ele obtinha o "título de Rei", nem era

"[...] fruto da reunião das outras familias à sua, pois que não [possuia] sobre todas mais que o poder e os direitos que a natureza the tem já concedido sobre seus filhos, de quem ela o cria Rei, fazendo-o Pai".

A sua referência à natureza dizia respeito a um estado anterior à própria fundação do pacto social, por isso, os "[...] materiais de que se servem los chefes, reis, pais] para a construção de um edificio são mais antigos que o mesmo edifício [...]". Igualmente, a "sociabilidade" era uma caracteristica natural do homem que o motivava à associação, quando o "chefe" ou "pai" assumia a condição de rei.

Civique de Gastine narrava que na "infância", os filhos - ou o "povo", no início dos tempos ainda eram "débeis no físico e moral", porque eram dotados de poucas "luzes", simplesmente pelo pouco tempo de sua existência. Nesse estado, restava aos infantes apenas "obedecerem cegamente" ao pai que, no auge de sua virilidade, tinha condições de mandar e ser respeitado por sua "reconhecida superioridade física e moral". Por força da natureza, com o "avançar da idade", as capacidades "físicas e morais" do pai começavam a declinar, enquanto os filhos "amadureciam". "Bem depressa", "conheciam" que os seus interesses já não eram os mesmos de seu pai e, por isso, passavam, aos poucos, a não executar mais seus trabalhos de maneira "mecânica". ${ }^{27}$

Quando os filhos alcançavam a "virilidade" e o pai declinava à "decadência", ambos percebiam as diferenças de condições entre eles. O "pai" tomava a iniciativa e consultava os mais velhos que lhe transmitiam os "conselhos" e a "experiência do passado" para a sua ponderação sobre as transformações pelas quais estava passando. Segundo Civique de Gastine, "[...] este momento precede aquele que deve brotar o germe das ideias liberais [...]", "os filhos crescendo [ofereciam] a imagem exata de um Estado que se civiliza". Com o passar do tempo, alguns dos filhos instruíam-se em "artes e ciências", quando era chegado o estágio, em que o chefe - pai - reconhecia "[...] a necessidade indispensável de representação nacional, que se compõe naturalmente dos mais instruídos e mais sábios de seus filhos [...]".28

De acordo com o autor, o "povo" e o rei reconheciam esse momento da "representação nacional" simplesmente, porque se realizavam os designios de Deus. De forma semelhante ao que ocorreu com Moisés que se aliou aos israelitas para libertar da escravidão o Egito, o autor francês afirmava que Deus tinha "ideias liberais", sendo uma "Assembleia do Povo, ou seus Representantes" "justa", "legítima" e "santificada pela presença de Deus, que a preside sempre invisivelmente".29 Nesse sentido, descrevia o episódio que considerava fundador da lei: o recebimento por Moisés dos mandamentos de Deus. Para o autor, ele teria lido as "ordens" recebidas do Criador para o "povo" que, convicto de que "lhe convinham, e que não tinham nada contrário a seus usos e costumes", "se obrigou com solene e sagrado juramento de as observar", selando a "aliança legal entre Deus e o Povo de Israel". Assim, Civique de Gastine demonstrava que o primeiro "povo cristão" considerava o "Eterno" um "Deus Constitucional" e a lei, o "Árbitro". 
Com essas considerações, Civique de Gastine sacralizava a fundação da monarquia constitucional, sobretudo, as "ideias liberais, e os principios de uma sábia Liberdade apoiada pela Lei, e dirigida por ela". Desse modo, não se podia "condenar" e "rejeitar" a "Lei" sem cometer "horrivel sacrilégio". O autor manejava o poder divino do rei para dizer que "[...] se os Reis são a imagem de Deus sobre esta terra de miséria e perseguição [...]" deveriam seguir o exemplo de Moisés e dar "liberdade" ao "povo", mantendo-o sob o governo de "leis", porque o primeiro legislador cristão "[...] não era neste mundo a imagem de Deus, se não quando comandava homens livres!". Foi Moisés quem escreveu todas as "[...] ordens do Senhor com o consentimento do Povo", princípio necessário para legitimar qualquer lei e definido por um "Deus liberal", "de paz" e "liberdade". Assim, assinalava que os poderes do rei não deveriam ser "[...] mais extensos do que os do Deus, de quem ele os tem [...]", bem como demarcava a necessidade do consentimento dos "povos" para as "leis", o que garantia a sua "liberdade" sob o seu governo. ${ }^{30}$

A apropriação da Bíblia enquanto fonte histórica era algo recorrente nas obras que narravam uma linha evolutiva entre passado e presente, marcadas pelo surgimento do governo cristão (KOSELLECK, 1999, p. 19-48). Em Civique de Gastine, a narração das "Escrituras Sagradas" assinalava a admissão pelo "chefe" da necessidade de transformação do governo da monarquia absoluta para a constitucional, isto é, do mando concentrado no rei para um governo também com "representação nacional". Assim, os poderes do pai passavam aos filhos pela combinação de sua "bondade e debilidade". Forçado pela natureza, pelo avanço natural de sua idade que o levava à decrepitude de suas "forças morais e físicas", somado à virilidade das mesmas em seus filhos, o pai percebia as mudanças e agia com eles. Os filhos buscavam as "luzes" e ao pai restava admitir a sua condição e conduzir a formação da representação nacional.
No momento da fundação do pacto, o pai, chefe ou rei igualava-se a seus filhos ou "povo" e abria mão do seu anterior "direito natural de dominação" e se tornavam amigos. ${ }^{31}$ Nessa concepção, a transição da monarquia "despótica" à constitucional deveria ocorrer de modo "natural", com adesão do povo e do rei, o que Soares Lisboa projetava, em maio de 1822, na aceitação pelo príncipe regente $\mathrm{D}$. Pedro do pedido de convocação de Cortes do Brasil, encaminhado pela Representação dos Povos do Rio de Janeiro. Desse modo, de acordo com a obra de Civique de Gastine, quando existia o reconhecimento de ambas as partes das mudanças dos tempos, não havia motivo para qualquer "revolução". Nesse sentido, para Civique de Gastine, as revoluções eram o produto da "insistência" do rei em não enxergar as mudanças produzidas pela "natureza" e que configuravam um "novo tempo".

Os reis deveriam aceitar uma "representação nacional" para definir as leis e "[...] despojar-vos voluntariamente de uma parte dos vossos direitos; [e] se tardares demasiado, ocasionareis revoluções, que vó-los arrebatarão todos". Caso contrário, essa "cegueira" convertia-se em "despotismo" e na "péssima maneira com que os Povos são governados". De acordo com essa concepção "As revoluções são sempre obra dos governantes e nunca dos governados [...]", resultado de um governo "[...] oposto às suas luzes, e ao grau de liberdade, ao qual a natureza lhes tem dito que eles têm direito a pretender".32 Ao considerar que, na fundação do pacto social, não era o "povo" que se despojava de uma porção de sua liberdade natural para ingressar na sociedade, o autor francês diferenciava-se de grande parte dos autores contratualistas ou dos que compõem a "Escola de Direito Natural" (BOB$\mathrm{BIO}, 1994$, p. 13-14). No entendimento particular de Civique de Gastine, o rei era quem deveria renunciar a uma parte de seus "direitos naturais" que definiam a dominação do "povo" por sua "debilidade física e moral". Para constituir a monarquia constitucional, o poder real se reduzia conforme a "nação" se di- 
rigisse às "luzes" e à "civilização", sendo a relação entre o rei, os súditos e os "graus de liberdade" de seus poderes determinada e intermediada pela lei que "reina" sobre "povo" e rei: "É uma verdade eterna e incontestável que cada passo que dá uma Nação para as luzes da civilização, seu Soberano desce um degrau do trono [...]",33

Assim, a marcha natural em busca da "liberdade" era o que transformava a história ou o governo. A monarquia constitucional legitimava-se por ser naquele "grau de amadurecimento do povo" o governo que mais se adequava ao seu estado de "civilização". Nesse aspecto, essa concepção convergia com os discursos orientados para a definição do "bom governo", sendo uma forma de moderar democracia e o poder centralizado em detrimento de um republicanismo ilustrado, o que se conciliava com a tradição dominante no pensamento ilustrado português e luso-brasileiro (LEITE, 200; NEVES, 2003). Contudo, a formulação de Civique de Gastine continha na provisoriedade do "melhor governo" a expectativa de transformação em direção a uma crescente liberdade que se concretizaria com a redução do poder real, tornando possivel aos leitores a visualização da sua "descida" do trono, superando a monarquia.

Essa projeção, somada ao entendimento do despojar voluntário dos "direitos do rei" quando aceitava a reunião de uma "representação nacional" para definir a lei, sem nenhum tipo de alienação dos direitos do "Povo" no estabelecimento do pacto social, são os elementos mais particulares da obra de Civique de Gastine que contribuíram para a construção de uma memória radical e republicana sobre a trajetória pública de João Soares Lisboa. Nesse sentido, apresentava-se o entendimento de um tempo linear que transgredia a tradição do equilíbrio institucional dos poderes políticos contida na ideia de "melhor governo" e se realizaria no futuro. Esse ponto é o que Silvia Carla Pereira Fonseca identifica na ideia de república nos jornais das primeiras décadas do Império do Brasil e era característico do que Koselleck define como "conceito de movimento", marca da modernidade (FONSECA, 2004, p. 347; KOSSELECK, 2006, p. 267-303). Dessa forma, de certa maneira, o Correio do Rio de Janeiro antecipava o debate federalista de 1824 ou do Período Regencial. Segundo Morel, Soares Lisboa foi "um dos precursores do ideário radical dos liberais Exaltados" (MOREL, 2017, p. 249).

\section{Considerações finais}

A publicação no Correio do Rio de Janeiro da tradução das reflexões de Civique de Gastine tinha a função de definir indiretamente e de maneira pública o pacto social, os significados de seus termos centrais e suas expectativas para a monarquia constitucional do Brasil. Também preparava e teorizava sobre os significados politicos da redação e organização da Representação dos Povos do Rio de Janeiro, a transformação do governo em monarquia constitucional e a rearticulação dos laços coloniais. Na fundamentação do pacto, para Civique de Gastine, os direitos naturais eram "inalienáveis" e subordinavam a sociedade às "leis imutáveis e eternas da natureza"; ele dava protagonismo ao "Povo" e mantinha a autoridade moral dos ensinamentos religiosos no estabelecimento da monarquia constitucional, definida pelo movimento natural e inevitável de "amadurecimento das forças físicas e morais" do "povo" e do rei. Ademais, de acordo com Civique de Gastine, os "povos" e "nações" desenvolviam-se conforme uma lógica ou "razão natural" de "amadurecimento" do "povo" e que poderiam ser observadas pelo exame da natureza e do corpo social mais primordial: a familia. Entrava em cena uma "nova lógica", fundada na "razão natural" e conhecida por todos capazes de autorreflexão.

Dessa maneira, a seleção de autores mencionados no Correio do Rio de Janeiro não é definida por sua tentativa de escamoteação na imprensa de seu "republicanismo" ou por sua "autocensura" (LEITE, 2000, p. 42), mas muito mais pela escolha de autores, como Civique de Gastine. Soares Lisboa seguia sua preferência por um tipo de linguagem e de conteúdo que tem relação com 
a identificação em Liberté des Peuples et des Droits des Monarques Appelés à les Gouverner de elementos de sua formação letrada mercantil nele internalizados, tais como condutas morais, o apreço pela negociação, o entendimento do comércio como elo de "civilização" e "sociabilidade" dos "povos" ou mesmo um estilo argumentativo que utilizava, por exemplo, a metáfora da "família" e a associação entre a administração da casa e o governo dos povos. Com essas publicações da obra do autor francês, estavam implícitos alguns referenciais que, manejados pelo redator do Correio do Rio de Janeiro, permitiam a divulgação do que entendia como "Natureza" e leis naturais, basilares na sua compreensão de representação e participação política em um espaço cívico.

Em 1822, com a publicação das traduções da obra de Civique de Gastine, Soares Lisboa preparava o público para a organização e o pedido de convocação de Cortes do Brasil registrado na Representação do Povo do Rio de Janeiro, engajando-se na transformação do governo da Coroa em uma monarquia constitucional. Pode-se dizer que, nesse momento, defendia um posicionamento moderado de uma passagem natural à monarquia constitucional independente, que ele enxergava e pretendia divulgar. Ao mesmo tempo, os aprendizados com a obra do autor francês ofereceram ao redator elementos para imaginar um governo no qual o "Povo" era um ator político, aventando a ampliação da participação e representação em busca pela "liberdade". Essa perspectiva se desenvolveu em uma definição de espaço cívico, com a defesa do mérito e da cidadania, baseada na valorização das virtudes morais e civicas e o modo direto de eleição dos deputados às Cortes do Brasil. A publicação dessas ideias sinalizava expressões liberais mais radicais que foram mobilizadas por opositores de Soares Lisboa para qualificá-lo, por exemplo, como republicano ou jacobino. Depois do fechamento da Assembleia Legislativa por D. Pedro I, em 1824, essas elaborações e convicções políticas convergiram para a adesão de Soares Lisboa à Confederação do Equador. Por sua vez, na trajetória de Civique de Gastine, em outro campo de debate, o radicalismo liberal culminou em abolicionismo (FERREIRA, 2017, p. 147-172, 295-352).

\section{Referências}

ALEXANDRE, Valentim. Os sentidos do império. Questão nacional e questão colonial na crise do Antigo Regime português. Porto: Afrontamento, 1993.

ALMEIDA, Gabriela Berthou. Jogos de poder: disputas em torno da administração do Seminário de Mariana, 1829-1835. In: SIMPÓSIO NACIONAL DE HISTÓRIA: CONHECIMENTO HISTÓRICO E DIÁLOGO SOCIAL, 27., 2013, Natal. Anais [...]. Natal: [s. n.], 2013. Disponível em: http://www.snh2013.anpuh.org/resources/ anais/27/1371332851_ARQUIVO_textoanpuh-revisado-final.pdf. Acesso em: 20 fev. 2015.

BHERING, Antonio Ribeiro. O Novo Argos, Minas Gerais, n. 6, 18 dez. 1829. Disponivel em: https://books.google. com.br/. Acesso em: 9 maio 2015.

BLANCHARD, Pedro. Tesouro de Meninos obra dividida em três partes: moral, virtude e civilidade. Lisboa: Tip. de José da Rocha, 1851.

BOBBIO, Norberto; BOVERO, Michelangelo. Sociedade e Estado na Filosofia Política Moderna. São Paulo: Brasiliense, 1994.

DARNTON, Robert; ROCHE, Daniel (org.). Revolução Impressa: a imprensa na França 1775-1800. São Paulo: Edusp, 1996.

DONGHI, Tulio Halperín. Historia contemporánea de América Latina. Madrid: Alianza Editorial, 2005.

Fernández SEBASTIÁN, J. Liberalismo nacientes em el atlântico iberocamericano: "liberal" como concepto y como identidad política, 1750-1850. In: Fernández SEBASTIÁN, J. (org.). Diccionario politico y social del mundo iberoamericano. La era de las revoluciones, 1750-1850. Madrid: Fundación Carolina: Sociedad Estatal de Conmemoraciones Culturales: Centro de Estudios Politicos y Constitucionales, 2009. p. 695-731. https:// doi.org/10.7767/jbla.2008.45.1.149.

FISKE, John; WILSON, James Grant. Cyclopaedia of American Biography. New York: D. Appleton and Company, 1887.

GASTINE, Civique de. De la liberté des peuples et des droits des monarques appelés a les gouverner. Paris: Chez les Marchands de Nouveautés, 1818.

GUERRA, François Xavier. «Voces del pueblo». Redes de comunicación y origenes de la opinión en el mundo hispánico (1808-1814). Revista de Indias, [s. l.], v. 62, n. 225, p. 357-384, 2002.

HOEFER, M. le (dir.). Nouvelle biographie générale: depuis les temps les plus reculés jusqu'à nos jours. Paris: MM. Firmin-Didot Frères, 1852.

KOSELLECK, Reinhart. Estratos do Tempo: Estudos sobre o Tempo. Rio de Janeiro: Contraponto: Ed. PUC Rio, 2014. 
KOSELLECK, Reinhart. Futuro Passado: contribuição à semântica dos tempos históricos. Rio de Janeiro: Contraponto: Ed. PUC Rio, 2006.

KOSELLECK, Reinhart. Critica e crise: uma contribuição à patogênese do mundo burguês. Rio de Janeiro: Contraponto: Ed. UERJ, 1999.

JANCSÓ, István; PIMENTA, João Paulo G. Peças de um mosaico (ou apontamentos para o estudo da emergência da identidade nacional brasileira). In: MOTA, Carlos Guilherme (org.). Viagem incompleta: a experiência brasileira (1500-2000). São Paulo: Senac, 2000. p. 127-175

LEITE, Renato Lopes. Republicanos e libertários: pensadores radicais no Rio de Janeiro, 1822. Rio de Janeiro: Civilização Brasileira, 2000.

LISBOA, João Soares. Correio do Rio de Janeiro, Rio de Janeiro, 1822. Disponivel em: bndigital.bn.gov.br/ hemeroteca-digital/. Acesso em: 22 maio 2020.

LUSTOSA, Isabel. Insultos impressos: a guerra dos jornalistas na Independência, 1821-1823. São Paulo: Companhia das Letras, 2000.

MAHUL, A. Annuaire nécrologique ou complément annuel et continuation de toutes les biographies ou dictionnaires historiques. Paris: Ponthieu: Libraire: Palais-Royal, 1823.

MENDONÇA, Manuel Teixeira Cabral de. O Guarda-livros moderno, ou curso completo de instruções elementares sobre as operações do comercio. Lisboa: Impressão Régia, 1823.

MOREL, Marco. A Revolução do Haiti e o Brasil escravista: o que não deve ser dito. Jundiaí: Paco, 2017.

MOREL, Marco. Nação e revolução: o rubro veio historiográfico no Brasil na primeira metade do século XIX. In: CHAVES, C. M. DAS G.; SILVEIRA, M. A. (org.). Território, conflito e identidade. Belo Horizonte: Argumentum, 2007. p. 181-204

MOREL, Marco. As transformações dos espaços públicos: imprensa, atores políticos e sociabilidades na cidade imperial, 1820-1840. São Paulo: Hucitec, 2005.

NEVES, Lucia Maria Bastos Pereira das. Corcundas e constitucionais: a cultura política da independência, 1820-1822. Rio de Janeiro: FAPERJ, 2003.

PEDREIRA, Jorge Miguel de Melo Viana. Os homens de negócio da praça de Lisboa de Pombal ao vintismo (1755-1822). Diferenciação, reprodução e identificação de um grupo social. 1995. Tese (Doutorado) - Curso de Sociologia e Economia Históricas, Faculdade de Ciências Sociais e Humanas, Universidade Nova de Lisboa, Lisboa, 1995.

PIMENTA, João Paulo G. A independência do Brasil e a experiência hispano-americana (1808-1822). São Paulo: Hucitec/FAPESP, 2015

PIMENTA, João Paulo G. Una América Latina por sus espacios y tiempos. Prismas: Revista de Historia Intelectual, [s. l.], v. 15, n. 2, p. 229-231, 2011.

PIMENTA, João Paulo G. História dos conceitos e história comparada: elementos para um debate. Almanack Braziliense, [s. l.], n. 07, p. 56-60, 2008. https://doi. org/10.11606/issn.1808-8139.voi7p56-60.
PITTS, Jennifer. Republicanism, liberalism and empire in post-revolutionary France. Empire and Modern Political Thought. Cambridge: Sankar Muthu. Cambridge UP, 2012.

QUIJADA, Mônica. Modelos de interpretación sobre las independencias hispano-americanas. México: Consejo Nacional de Ciencia y Tecnología, Universidad Autónoma de Zacatecas, 2005

RABGE, Alphonse; BOISJOLIN, Claude-Augustin Vieilh de; SAINT-PREUVE, François de. Biographie Universelle Et Portative Des Contemporains Ou Dictionnaire Historique Des Hommes Vivants Et Des Hommes Morts Depuis 1788 Jusqu'A Nos Jours, Qui Se Sont Fait Remarquer Par Leur Ecrits, Leurs Actions, Leurs Talents, Leurs. Paris: Chez l'Éditeur, 1836.

SCHIAVINATTO, lara Lis. Educação Sensivel. Memória, imagem e politica no mundo luso-brasileiro. Campinas: Universidade Estadual de Campinas, 2017. Tese de livre docência, cedida pela autora.

TOMICH, Dale, O Atlântico como espaço histórico Estudos Afro-asiáticos, [s. l.], n. 2, p. 221-240, 2004.

VAZ, Francisco António Lourenço. Instrução e economia: as ideias económicas no discurso da ilustração portuguesa (1746-1820). Lisboa: Edições Colibri, 2002.

\section{Paula Botafogo Caricchio Ferreira}

Doutora em História pela Universidade Estadual de Campinas (Unicamp), pesquisadora de pós-doutorado com bolsa FAPESP no Departamento de História da Universidade de São Paulo (USP) em São Paulo, SP, Brasil.

\section{Endereço para correspondência}

Paula Botafogo Caricchio Ferreira

Rua Tapuias, 120, apto 94, bloco 2

Socorro, 04763-080

São Paulo, SP, Brasil 